Adolescent athletes with learning disability display atypical maturational trajectories on concussion baseline testing : Implications based on a Finnish sample

\author{
Peltonen, Kati
}

2019-04-03

Peltonen , K, Vartiainen , M , Laitala-Leinonen , T , Koskinen , S , Luoto , T , Pertab , J \& Hokkanen , L 2019 , ' Adolescent athletes with learning disability display atypical maturational trajectories on concussion baseline testing : Implications based on a Finnish sample ' , Neuropsychology, Development, and Cognition. Section C: Child Neuropsychology , vol. 25 , no. 3 , pp. 336-351 . https://doi.org/10.1080/09297049.2018.1474865

http://hdl.handle.net/10138/309245

https://doi.org/10.1080/09297049.2018.1474865

unspecified

acceptedVersion

Downloaded from Helda, University of Helsinki institutional repository.

This is an electronic reprint of the original article.

This reprint may differ from the original in pagination and typographic detail.

Please cite the original version. 


\section{Adolescent athletes with learning disability display atypical maturational trajectories on concussion baseline testing: Implications based on a Finnish sample}

Kati Peltonen ${ }^{\mathrm{a} *}$ Matti Vartiainen ${ }^{\mathrm{a}}$, Tiina Laitala-Leinonen ${ }^{\mathrm{b}}$, Sanna Koskinen ${ }^{\text {a }}$, Teemu Luoto ${ }^{c}$, Jon Pertab ${ }^{d} \&$ Laura Hokkanen ${ }^{a}$

${ }^{a}$ Department of Psychology and Logopedics, University of Helsinki, Helsinki, Finland;

${ }^{b}$ Institute of Biomedicine, University of Turku, Turku, Finland; ${ }^{c}$ Department of Neurosurgery, Tampere University Hospital, Tampere, Finland; ${ }^{d}$ Neurosciences Institute, Intermountain Healthcare, Utah, USA

* University of Helsinki, Department of Psychology and Logopedics, Address: P.O. Box 63, 00014, University of Helsinki, Finland E-mail: kati.peltonen@helsinki.fi 


\section{Adolescent athletes with learning disability display atypical maturational trajectories on concussion baseline testing: Implications based on a Finnish sample}

Objective: Previous research has reported lower cognitive test scores on baseline testing in athletes reporting multiple previous concussions or a history of learning disability (LD). Age also has an important influence on cognitive performance. While these factors have been considered individually in previous studies, the present study is the first to explore the interaction of age, self-reported LD, and history of concussion on baseline Immediate Post-Concussion Assessment and Cognitive Testing (ImPACT®) in a nationwide study of adolescent athletes.

Methods: ImPACT® was administered to 1823 Finnish male ice hockey players (aged 12-21 years old) prior to the 2015-2016 or 2016-2017 playing seasons. Linear regressions and simple slopes analyses were used for clarifying the impact of LD and previous concussion history on maturational trajectories.

Results: In comparison to typically developing athletes, athletes with LD had lower neurocognitive scores in all composites and differing maturational trajectory in verbal memory and visual motor speed. The number of previous concussions did not impair neurocognitive performance at baseline assessment.

Conclusions: Application of standard age based norms to adolescent athletes with a history of LD has the potential to negatively skew clinical decision making. Separate reference values for LD athletes are warranted due to their unique developmental cognitive trajectories. The reference values for the Finnish participants in this study are presented.

Keywords: sport, concussion, learning disability, ImPACT®, baseline testing 


\section{Introduction}

Appropriate clinical management of athletes with sport-related concussion (SRC) is important to increase player safety and minimize the potential for possible long-term deficits (Davis et al., 2017; Halstead, Walter \& The Council on Sports Medicine and Fitness, 2010; McCrory et al., 2017). Effective concussion management is especially important when the injury occurs in the developing young athlete (Brown et al., 2014). The peak ages for concussions are in adolescence and young adulthood (Langlois, Rutland-Brown \& Thomas, 2005). There are estimates, that 2.5 concussions occur across all sports for every 10000 athletic exposures, where athletic exposure means one athlete takes part in one game or training (Guerriero, Proctor, Mannix \& Meehan, 2012). Besides American football, one of the sports with the highest risk for SRC in youth is ice hockey where the incidence rate in high school age players is 6.2 concussions for every 10000 athletic exposures (Guerriero et al., 2012).

Cognitive assessment has been promoted as one of the tools that can enhance clinical decision making in SRC management (McCrory et al., 2012). Among the many available computerized neurocognitive tests in concussion management, Immediate Post-Concussion Assessment and Cognitive Testing (ImPACT®) is one of the internationally most utilized. There is research supporting its reliability, sensitivity, and validity in the concussed population (Elbin, Szhatz \& Covassin, 2011; Iverson 2005; Maerlander et al., 2010; Schatz \& Putz, 2006; Schatz \& Sandel, 2013). However, some studies indicate only modest test-retest reliability and low sensitivity beyond a brief post-injury window (Broglio, Ferrara, Macciocchi, Baumgartner \& Elliott, 2007; Nelson et al. 2016b). The clinical utility of ImPACT® however, similar to other computerized 
tests, is best very soon after injury or after symptom resolution and limited at later time points (Nelson et al. 2016b).

Due to the observation that there is wide variability in the premorbid cognitive functioning of individual athletes, some organizations have adopted baseline, pre-season cognitive testing protocol for their athletes. Pre-season results can be used as a more accurate estimate of the athlete's pre-injury cognitive functioning than would be gleaned from other sources and can aid in the interpretation of post-injury scores (Van Kampen, Lovell, Pardini, Collins \& Fu, 2006). However, baseline testing is resourceconsuming and is rarely available in recreational sports. In the absence of baseline testing, population-specific normative values are employed to evaluate whether the injured athlete's post-injury cognitive assessment scores are atypical. This information is incorporated into the decision making process for clinical management of the injured athlete.

It is well known that cognitive performance in adolescence improves with increasing age (Gioa, Janusz, Gilstein \& Iverson, 2004; Hunt \& Ferrera, 2009; Maruff, Collie, Anderson, Mollica, McStephen \& McCrory, 2004). Any statistical decision about whether cognition is atypical following concussion should include an adjustment for developmental changes in cognition (McCrory et al., 2004). For instance a baseline score taken 20 month prior to injury should be adjusted by the anticipated interim cognitive improvement in that domain if it is to be an effective comparison for postinjury cognitive test results. Anticipated improvement can be gleaned from normative group maturational curves. Adolescence is a time of rapid cognitive development in some domains and this highlights the importance of narrow age bands in normative groupings or use of continuous modeling procedures. 
In making the decision about appropriate reference values, it is also important to identify subgroups of individuals that may have an atypical developmental trajectory compared to the wider group norms. Individuals with diagnosed learning disabilities (LD) display atypical developmental trajectories thought to be due to central nervous system dysfunction (Nicolson et al., 1999; Silver et al., 2008). Learning disability (LD) is defined as a heterogeneous group of disorders consisting difficulties in the acquisition and use of listening, speaking, reading, writing and reasoning, or mathematical abilities and which is traditionally diagnosed in early childhood (DSM-5; American psychiatric Association, 2013). Lower scores on baseline neurocognitive tests in athletes with LD have been reported and separate normative data on ImPACT® has been provided for this specific subgroup for English speaking populations (Elbin, Kontos, Kegel, Johnson, Burkhart \& Schatz, 2013; Zuckerman, Lee, Odom, Solomon \& Sills, 2013). Maturational adjustments and the presence or absence of LD are both important in considering the relevance of post-injury test scores.

Concussion history is another important variable to consider as a modifier in interpretation of post-injury cognitive test scores. There is debate as to whether the number of previous concussions should be used as an adjusting factor when comparing post-injury scores to normative comparison groups. There are many studies examining the effect of previous concussion on cognitive performance across the lifespan. Some of these studies have not identified differences related to multiple concussions (Brooks et al., 2013, Broglio, Ferrara, Piland \& Anderson, 2006, Iverson, Brooks, Lovell \& Collins, 2006), while others have reported that athletes with a remote history of multiple concussion have lower cognitive test scores and lingering post-concussive symptoms in preseason testing (Elbin et al., 2012; Iverson, Echemedia, LaMarre, Brooks \& Gaetz, 
2012; Iverson, Gaetz, Lovell \& Collins, 2004; Nelson et al., 2016a; Schneider, Emery, Kang, Schneider \& Meeuwisse, 2010).

While there is evidence that both learning disability and history of multiple concussions are associated with lowered baseline cognitive functioning (Collins et al., 1999), it is still unclear whether these variables are synergistic. The present study was designed to explore the interaction effects of age, learning disability, and previous concussion history on pre-season baseline cognitive performance in a large Finnish sample. While these factors have been considered individually in previous studies, the present study is the first to explore the interaction of these variables on baseline cognitive test scores in a nationwide scale. The hypothesis was that the number of concussions together with the learning disability would cumulatively impair neurocognitive performance at baseline, and that LD would cause atypical developmental trajectory in at least some of the cognitive domains. Current analysis was designed to model maturational cognitive change among LD group and among typical learners and to tabulate Finnish reference values for ImPACT® for various age subgroups using a large geographically representative sample.

\section{Methods}

\section{Participants}

As part of their SRC management initiative, the Finnish Ice Hockey Association adopted a policy of encouraging baseline testing for all representative team athletes between the ages of 12 and 21 years. ImPACT® was administered to 1823 Finnish male ice hockey players prior to the 2015-2016 or 2016-2017 playing seasons. Some athletes 
participated on both assessments, but only the first test results were included in the present analysis. The athletes came from 89 teams and every representative team in the national hockey league nationwide participated in the study. Athletes were tested in Finnish language in small groups (max 6 people per group). The test was conducted in a quiet environment, at least 15 minutes after exercise and between the hours of $8 \mathrm{am}$ and $7 \mathrm{pm}$. Athletes were wearing headphones in the test situation. Tests were administered by a health care professional or a health care professional student trained to administer the test.

As participation in this study was voluntary, not all athletes within each team completed preseason baseline testing, but refusals were rare, estimated to be less than $5 \%$ based on no-show rates. Minimum performance requirements were set to insure that only athletes who demonstrated understanding of the ImPACT® test battery were included. Some athletes $(n=26)$ were excluded from the analysis because of invalid test scores suggested by the ImPACT® validity criteria (Impulse Composite Score >30). Athletes were also excluded based on the presence of psychiatric disorders $(n=5)$. The study was approved by the Ethical Committee of the Helsinki Uusimaa Hospital District, and each participant and a parent / guardian signed a written informed consent according to the Declaration of Helsinki.

\section{Procedures}

Cognitive functioning was assessed with the ImPACT® computerized neurocognitive test battery (Online version; ImPACT Applications Inc.). The battery consists of 6 individual test modules measuring attention, memory, reaction time, processing speed, learning and executive functioning (ImPACT Applications, Inc.). ImPACT® provides 
composite scores for verbal and visual memory, visual motor speed, reaction time and impulse control, and also includes a Total Symptoms Score describing the severity of subjective symptoms.

Background information was collected before cognitive testing: age, playing position, history of learning disability, history of ADHD or ADD, neurological history, migraine history, hours slept the night before, history of psychiatric illness and concussion history expressed as number of previous concussions. Learning disability was defined as having a diagnosis of dyslexia or learning disability. Categorization was based on athletes' self-report of presence or absence of these conditions on a questionnaire. Individuals with self-reported ADHD or ADD $(n=13)$ were excluded. The reference values generated were based on chronological age bands of one year.

\section{Data Analysis}

The level of statistical significance was set at 0.05 . All analyses were performed using IBM SPSS Statistics 24.0 (IBM Corp. Armonk, NY, USA). Preliminary analyses including Kolmogorov-Smirnov and Levene's test were conducted to confirm that the assumptions underlying the parametric statistical procedures were met.

The independent t-test was used to determine whether LD group and typical learners performed differently on ImPACT® test. To find the significant variables to include in the predictor model, linear regressions with age and concussion history were calculated to model neurocognitive scores separately in LD and Typical learners group. The relationship between age, $\mathrm{LD}$ and their interaction on cognitive performance was 
then modelled. Linear regressions were completed to predict the effect of age, LD and their interaction on verbal memory, visual memory, visual motor speed, reaction time and on Total Symptoms Score. To interpret the moderation effect, the simple slopes analysis was carried out. Means and standard deviations were calculated within each age group. Two extreme values on Total Symptoms Score in LD group were replaced by the mean score of this age group.

\section{Results}

Total of 108 players reported LD, 1715 were typical learners. The groups did not differ in age, years of education or the number of past concussions or in hours of sleep at previous night, see Table 1. In the Typical learners group 5.5\% and in the LD group $12.8 \%$ reported having a history of migraine $\left[\chi^{2}(1)=11.69, \mathrm{p}<.01\right]$. Typical learners obtained better neurocognitive scores on ImPACT $®$ compared to the LD group (Table $1)$.

\section{[INSERT TABLE 1. HERE]}

Linear regressions were calculated to predict neurocognitive scores based on age and concussion history separately in LD and Typical learners' groups. The results of regression analysis indicated that the age significantly predicted most of the neurocognitive scores in both groups, and the Total Symptoms Score in the Typical learners group. The concussion history did not predict any of the neurocognitive scores in either group but significantly predicted Total Symptoms Score in Typical learners. Table 2 summarizes the analysis results. 
[INSERT TABLE 2. HERE]

A multiple regression model was tested to investigate whether the association between age and neurocognitive scores depends on the LD status as shown in Table 3. A significant interaction effect was found on verbal memory, indicating that the relationship between age and verbal memory is moderated by learning disability. A simple slopes analysis was carried out to further examine the moderation. A significant positive relationship between age and verbal memory was found in Typical learners, $b=$ $.40,95 \%$ CI $[.12, .68], \mathrm{t}=2.81, \mathrm{p}=.01$, as well as in LD group, $\mathrm{b}=2.22,95 \%$ CI [.87, 3.57], $\mathrm{t}=3.23, \mathrm{p}<.01$ but the effect of age was stronger in LD group than in Typical learners (Figure 1.).

There was a significant interaction effect between age and LD also on visual motor speed. The simple slopes analysis revealed a significant positive relationship between age and visual motor speed in Typical learners, $b=1.30,95 \%$ CI [1.14, 1.47], $\mathrm{t}=15.60, \mathrm{p}<.01$, as well as in LD group, $\mathrm{b}=2.36,95 \% \mathrm{CI}[1.71,3.00], \mathrm{t}=7.20, \mathrm{p}<.01$ and again the effect of age was stronger in LD group than in Typical learners (Figure 1.).

[INSERT FIGURE 1. HERE]

There was no interaction effect between age and LD on visual memory, on reaction time, or on Total Symptoms Score (Table 3.).

[INSERT TABLE 3. HERE] 
The reference values ( $\mathrm{M}$ and $\mathrm{SD}$ ) for the ImPACT® baseline composite scores and the ImPACT® subtest by age are provided for typical learners (Table 4.), and for LD group in Table 5.

\section{[INSERT TABLE 4. HERE]}

[INSERT TABLE 5. HERE]

\section{Discussion}

The aim of this study was to examine the interaction of age, concussion history, and self-reported LD on baseline neurocognitive performance. The results indicate that athletes with LD obtain lower baseline neurocognitive scores on ImPACT® and develop at a different rate in several areas of cognition compared to typical learners as hypothesized. The results support the idea of separate age-specific normative values for athletes with LD due to their atypical developmental trajectory. The lower overall performance and more prominent changes over the course of adolescence has the potential to generate erroneous conclusions if a typically developing norm group was used for interpreting post-concussion test scores in athletes with LD. Contrary to our hypothesis, concussion history did not predict neurocognitive performance at the baseline assessment in either group. There was a trend for the LD group to report slightly higher number of prior concussions compared to typical learners, but the difference was not statistically significant.

The finding that LD athletes had lower test scores is consistent with prior research showing that children with reading disability as well as arithmetic disability show a significant lag in development of cognitive skills. Deficits have been reported in 
development of short term memory in LD samples (Moll, Göbel, Gooch, Landerl \& Snowling, 2016; Siegel \& Ryan, 1988; Siegel \& Ryan, 1989). While memory deficits have been consistently reported in reading disorders and in mathematics disorders, it is unclear which memory systems (verbal, visual or working memory) are most affected (Moll et al., 2016). Processing speed and executive functioning deficits have also been associated with learning disorders (Bonifacci \& Snowling, 2008; Bull \& Johnston, 1997; Catts, Gillispie, Leonard, Kail \& Miller, 2002; Silver et al., 2008). Findings in previous research of memory and processing speed deficits were consistent with the findings of the present research. The LD group obtained lower scores on verbal and visual memory, visual motor speed, and reaction time than typical learners, and the trajectories in verbal memory and visual motor speed showed a divergence between the two groups.

In post-concussion cognitive evaluation many athletes will not have completed baseline testing and normative values are relied on in interpreting the post-injury scores. Because athletes with LD have lower scores on cognitive measures at baseline (Nelson et al., 2016a; Zuckerman et al., 2013), the sole use of standard normative data in postinjury assessment can lead to false positives and unwarranted delays in return to play. Furthermore, including LD athletes in standard normative groups will tend to artificially deflate normative estimates that are applied to typically developing athletes - they may consequently be returned to play prematurely (Elbin et al., 2013). In this study, reference values for Finnish male junior ice hockey players with LD are presented. They can be used to aid the practitioner in the absence of baseline test scores. They may not be generalizable to female athletes with $\mathrm{LD}$, however, and reference values for other sports and other language and culture groups are also needed. 
The rate of change is also relevant in determining the timing of baseline testing. The results of the present study confirm separate maturational trajectories in verbal memory and visual motor speed. Due to differing developmental rates in cognitive functioning in adolescence the optimal spacing between baseline assessments may be smaller in LD groups than typical learners. The recommendation for adolescent athletes is to update baseline testing after two to three years to account for cognitive maturation (Collie, Maruff, Darby \& McStephen, 2003; Elbin et al., 2011). When comparing post injury scores to an athlete's baseline that was measured several years previously, group membership is a relevant variable to consider given differing rates of change over time. With these findings in mind, yearly baseline testing is important to enhance validity of baseline measures in youth populations and even more so in athletes with LD (Hunt \& Ferrera, 2009; Reynolds, Fazio, Sande, Schatz \& Henry, 2016). This recommendation is consistent with the findings of prior studies showing that maturation during adolescence and pre-adolescence contributes to dramatic changes in reaction time, processing speed, and executive control (Fry \& Hale, 2000; Reynolds et al., 2016).

Contrary to our hypothesis, the number of previous concussions did not predict neurocognitive performance at baseline assessment. Our findings in this area are consistent with some previous studies (Broglio et al., 2006; Brooks et al., 2013; Bruce \& Echemedia, 2009; Iverson et al., 2006) but not others (Belanger, Spiegel \& Vanderploeg, 2010; Collins et al., 1999; Iverson et al., 2004). The effect of concussion history on baseline neurocognitive performance was not statistically significant in this study. The lack of significance may reflect the limited power of this study, as only 67 athletes had a history of three or more concussions. There are many studies showing that neurocognitive alterations are not typically apparent until the third injury (Bruce \& Echemedia, 2009; Collins et al., 2002; Iverson et al., 2006) and the prevalence of 
athletes with 3 or more concussions in our sample was very low (under $4 \%$ of all participants).

It is notable that concussion history was associated with group membership the LD group reported a slightly greater number of lifetime concussions at baseline testing compared to typical learners, but the difference was non-significant $(\mathrm{p}=.06)$. This finding suggests that either a common underlying factor places this group at risk for both LD and concussion or conversely that the LD group's history of concussion may have hampered their subsequent learning. Previous research supports the idea that athletes with LD could be prone to concussions (Collins et al., 1999; Nelson et al., 2016a).

In addition to the cognitive test scores, we also looked at the Total Symptoms Score, provided by ImPACT®, to describe subjective symptoms of athletes. The LD group reported more symptoms at baseline compared to the Typical learners' group, as reported in previous studies (Elbin et al. 2013, Zuckerman et al., 2013). Interestingly, the LD group also reported history of migraine with a higher frequency. Subjective symptoms are the key component in post-concussion assessment and often measured using the SCAT sideline screening (SCAT3). It has been established in adults that many of the symptoms are present already at baseline (Harmon et al., 2013, Hänninen et al., 2016, Hänninen et al., 2017). Among the typical learners, both age and concussion history predicted cognitive performance, while no effect was seen in the LD group. The maturational trajectories appeared similar in both groups as there was no interaction between age and group membership.

The cognitive test used in our study (ImPACT®) is developed to detect cognitive deficits (i.e. memory problems, problems in concentrating and slowness of thinking) after a concussive injury. There are studies suggesting that it lacks sensitivity 
when individuals with extreme cognitive capacity (high or low) are compared to normative data (Rabinowitz \& Arnett, 2012; Schatz \& Robertshaw, 2014). One study has reported that male high school athletes with LD are more likely to have an invalid baseline score on ImPACT ${ }^{\circledR}$ reflecting exceptional poor or invalid performance (Schatz, Moser, Solomon, Ott \& Karpf, 2012). This phenomenon is supported by our clinical experience. Adding other measures of validity and effort may be beneficial in testing special populations. Overall, clinicians interpreting the cognitive test results should be sensitive to inherent individual differences in making return to play decisions. The ImPACT® test is a concussion screening measure, and should not be used alone for the management of SRC (McCrory et al., 2013, Nelson et al. 2016b), but combined with other objective measures, such as balance testing and symptom scales.

Some limitations of this research are worth noting. Future research would benefit from a longitudinal design for detecting age related change to avoid the limitations of the cross-sectional sampling that was used in this study. Clinical interview, objective academic testing, and even parent report would be a more robust method to establish history of LD. In this study only $6 \%$ of athletes self-reported LD, which may be an underestimation. A recent study suggests that data about LD gathered from collateral informants would have been more reliable than the self-nomination we used; only $9.5 \%$ of those who reported a learning disorder on a take-home preseason questionnaire completed by parents also reported a learning disorder during ImPACT ${ }^{\circledR}$ administration (McKay, Schneider, Brooks, Mrazik \& Emery, 2014). The stigma associated with learning disorders might affect responses on the ImPACT®, administered in a group setting (McKay et al., 2014).

An additional consideration is that we treated the LD group as homogeneous where in reality there was diversity in both the type of LD (for example, dyslexia and 
mathematical disability) and in the severity of the LD. Athletes indicated whether they had been diagnosed with a learning disability, but the details (e.g., etiology, nature and severity) of the diagnosis were not defined. The results of the present study have unclear generalizability to females (only males were sampled). There are studies suggesting that the gender might significantly affect neurocognitive performance at baseline (Covassin, Elbin, Larson \& Kontos 2012; Gur et al., 2012). Also, the present study employed only one assessment tool (ImPACT®) the findings may not generalize to other tools.

A clear strength of our study was the large, nation-wide sample. The similarity found between findings from other sports in other countries and our own findings supports the multi-national applicability of the findings of this study. The reference values found in our Finnish sample are very similar to those based on datasets gathered from US (Elbin et al., 2013; Zuckerman et al., 2013).

\section{Conclusions}

The results of this study highlight the importance of individual baseline testing in athlete populations that display high variability of performance or differing developmental trajectories over time - youth athletes and athletes with a learning disability display this high variability. The results and reference values provide practical data that can inform concussion management in parallel populations if individual baseline results are not available. Considering the rapid cognitive maturation in youth, normative reference values with one year age-bands are warranted for athletes with LD. Further research focusing on maturational cognitive change in specific populations will further improve the utility of cognitive testing in informing safe concussion management practices. 
Acknowledgements

This work was supported by the Ministry of Social Affairs and Health Finland (grant number 201510103) and Turku University Foundation. There are no conflicts of interest. 


\section{References}

American Psychiatric Association. (2013). Diagnostic and statistical manual of mental disorders $\left(5^{\text {th }}\right.$ ed.). Washington, DC: American Psychiatric Association Press.

Belanger, H.G., Spiegel, E. \& Vanderploeg R.D. (2010). Neuropsychological performance following a history of multiple self-reported concussions: A meta-analysis. Journal of the neuropsychological Society, 16, 262-267. doi:10.1017/S1355617709991287

Broglio, S.P., Ferrara, M.S., Piland, S.G. \& Anderson, R.B. (2006) Concussion history is not a predictor of computerized neurocognitive performance. British Journals of Sports Medicine, 40, 802-805. Retrieved from http://dx.doi.org/10.1136/bjsm.2006.028019

Broglio, S. P., Ferrara, M. S., Macciocchi, S. N., Baumgartner, T. A., \& Elliott, R. (2007). Test-Retest Reliability of Computerized Concussion Assessment Programs. Journal of Athletic Training, 42(4), 509-514.

Brooks, B.L., McKay, C., Mrazik, M., Barlow, K.M., Meeuwisse, W.H. \& Emery, C.A. (2013). Subjective, but not objective, lingering effects of multiple past concussions in adolescents. Journal of Neurotrauma, 30, 1469-1475. doi: 10.1089/neu.2012.2720 
Brown, M.J., Mannix, R.C., O’Brian, M.J., Gostine, D., Collins, M.W. \& Meehan, W.P. (2014). Effect of Cognitive Activity Level on Duration of Post-Concussion Symptoms. Pediatrics, 133 (2), e299-e304. doi:10.1542/peds.2013-2125

Bruce, J.M., \& Echemendia, R.J. (2009). History of multiple self-reported concussions is not associated with reduced cognitive abilities, Neurosurgery, 64, 100-106. Retrieved from https://doi.org/10.1227/01.NEU.0000336310.47513.C8

Büttner, G., \& Hasselhorn, M. (2011). Learning disabilities: Debates on definitions, causes, subtypes, and responses. International Journal of Disability, Development and Education, 58(1), 75-87. Retrieved from https://doi.org/10.1080/1034912X.2011.548476

Cohen, J. (1988), Statistical power analysis for the behavioral sciences $\left(2^{\text {nd }}\right.$ ed.). Hillsdale, NJ: Erlbaum.

Collie, A., Maruff, P., Darby, D. \& McStephen, M.G. (2003). The effects of practice on the cognitive test performance of neurologically normal individuals assessed at brief test-retest intervals. Journal of the International Neuropsychological Society, 9(3), 419428. doi:10.1017/S1355617703930074

Collins, M.W., Grindel, S., Lovell, M.R., Dede, D.E., Moser, D.J., Phalin, B.R. \& McKeag, D.B. (1999). Relationship Between Concussion and Neuropsychological Performance in College Football Players. JAMA, 282, 964-970.

doi:10.1001/jama.282.10.964 
Collins, M.W., Lovell, M.R., Iverson, G.L., Cantu, R.C., Maroon, J.C., \& Field, M. (2002). Cumulative effects of concussion in high school athletes, Neurosurgery, 51, 1175-1181. Retrieved from https://doi.org/10.1097/00006123-200211000-00011

Covassin, T., Elbin, R., Larson, E. \& Kontos, A. (2012). Sex and Age Differences in Depression and Baseline Sport-Related Concussion Neurocognitive Performance and Symptoms. Clinical Journal of Sport Medicine, 22 (2), 98-104. doi:

10.1097/JSM.0b013e31823403d2

Davis, G., Anderson, V., Babl, F., Gioia, G. A., Giza, C., Meehan, W., ... Zemek, R. (2017). What is the difference in concussion management in children as compared with adults? A systematic review. British Journal of Sports Medicine, 51, 949-957. doi: 10.1136/bjsports-2016-097415

Elbin, R.J., Covassin, T., Hakun, J., Kontos, A.P., Berger, K., Pfeiffer, K. \& Ravizza, S. (2012). Do brain activation changes persist in athletes with a history of multiple concussions who are symptomatic? Brain Injury, 26 (10), 1217-1225. Retrieved from https://doi.org/10.3109/02699052.2012.672788

Elbin, R.J., Kontos, A.P., Kegel, N., Johnson, E., Burkhart, S. \& Schatz, P. (2013). Individual and Combined Effects of LD and ADHD on Computerized Neurocognitive Concussion Test Performance: Evidence for Separate Norms. Archives of Clinical Neuropsychology, 28, 476-484. doi:10.1093/arclin/act024 
Elbin, R.J. Schatz, P. \& Covassin, T. (2011). One-year test-retest reliability of the online version of ImPACT in high school athletes. American Journal of Sports Medicine, 39, 2319-2324. Retrieved from https://doi.org/10.1177/0363546511417173

Fry, A.F., \& Hale, S. (2000). Relationships among processing speed, working memory, and fluid intelligence in children. Biological Psychology, 54, 1-34. Retrieved from https://doi.org/10.1016/S0301-0511(00)00051-X

Gioa, G.A., Janusz, J.A., Gilstein, K. \& Iverson, G. (2004). Neuropsychological management of concussions in children and adolescents: effects of age and gender on ImPACT. British Journals of Medicine, 38, 657.

Guerriero, R.M., Proctor, M.R., Mannix, R. \& Meehan, W.P. (2012). Epidemiology, trends, assessment and management of sport-related concussions in United States high schools. Current Opinion in Pediatrics, 24, 696-701. doi:

10.1097/MOP.0b013e3283595175

Gur, R. C., Richard, J., Calkins, M. E., Chiavacci, R., Hansen, J. A., Bilker, W. B., . . . Gur, R. E. (2012). Age group and sex differences in performance on a computerized neurocognitive battery in children age 8-21. Neuropsychology, 26(2), 251-265. http://dx.doi.org/10.1037/a0026712

Halstead, M., Walter, K \& The Council on Sports Medicine and Fitness (2010). Clinical Report - Sport-Related Concussion in Children and Adolescents. Pediatrics, 126 (3), 597-615. doi:10.1542/peds.2010-2005 
Harmon, K.G., Drezner, J.A., Gammons, M., Guskiewicz, K.M., Halstead, M., Herring, S.A.,... Roberts, W.O. (2013). American Medical Society for sports medicine position statement: concussion in sport. British Journal of Sports Medicine, 47, 15-26. doi:10.1136/bjsports-2012-091941

Hunt, T. \& Ferrera, M. (2009). Age-Related Differences in Neuropsychological Testing Among High School Athletes. Journal of Athletic Training, 44(4), 405-409. doi:10.4085/1062-6050-44.4.405

Hänninen, T., Tuominen, M., Parkkari, J., Vartiainen, M., Öhman, J., Iverson G.L. \& Luoto T. (2016). Sport concussion assessment tool - 3rd edition - normative reference values for professional ice hockey players. Journal of Science and Medicine in Sport, 19(8), 636-641. Retrieved from https://doi.org/10.1016/j.jsams.2015.08.005

Hänninen, T., Parkkari, J., Tuominen, M., Iverson, G.L., Öhman, J., Vartiainen, M. \& Luoto, T.M. (2017). Interpreting change on the SCAT3 in professional ice hockey players. Journal of Science and Medicine in Sport 20(5), 424-431. Retrieved from https://doi.org/10.1016/j.jsams.2016.09.009

Iverson, G. L. (2005). Outcome from mild traumatic brain injury. Current opinion in Psychiatry, 18, 301-317. doi: 10.1097/01.yco.0000165601.29047.ae

Iverson, G.L., Gaetz, M., Lovell, M.R., \& Collins, M.W. (2004). Relation between subjective fogginess and neuropsychological testing following concussion. Journal of 
the International Neuropsychology Society, 10, 904-906.

doi:10.1017/S1355617704106139

Iverson, G.L., Brooks, B.L., Lovell, M.R., \& Collins, M.W. (2006). No cumulative effects for one or two previous concussions. British Journal of Sports Medicine, 40, 72 75. doi: 10.1136/bjsm.2005.020651

Iverson, G.L., Echemedia, R.J., LaMarre, A.K., Brooks, B.L. \& Gaetz, M.B. (2012). Possible lingering effects of multiple past concussions. Rehabilitation Research and Practice, vol. 2012, Article ID 316575, 1-8. doi:10.1155/2012/316575

Iverson, G., Gaetz, M., Lovell, M. \& Collins, M. (2004). Cumulative effects of concussion in amateur athletes. Brain Injury, 18(5), 433-443. Retrieved from https://doi.org/10.1080/02699050310001617352

Langlois, J.A., Rutland-Brown, W. \& Thomas, K.E. (2005). The incidence of traumatic brain injury among children in the United States: difference by race. Journal of Head Trauma Rehabilitation, 20(3), 229-238.

Maerlander, A., Flashman, L., Kessler, A., Kumbhani, S., Greenwald, R., Tosteson, T., \& McAllister, T. (2010). Examination of the Construct Validity of ImPACT Computerized Test, Traditional, and Experimental Neuropsychological Measures. The Clinical Neuropsychologist, 24, 1309-1325. Retrieved from https://doi.org/10.1080/13854046.2010.516072 
Maerlender, A.C., Masterson, C.J., James, T.D., Beckwith, J., Brolinson, P.G., Crisco, J. \& McAllister, T.W. (2016) Test-retest, retest, and retest: Growth curve models of repeat testing with Immediate Post-Concussion Assessment and Cognitive Testing (ImPACT). Journal of Clinical and Experimental Neuropsychology, 38(8), 869-874. Retrieved from https://doi.org/10.1080/13803395.2016.1168781

Maruff, P., Collie, A., Anderson, V., Mollica, C., McStephen, M. \& McCrory, P. (2004). Cognitive development in children: implications for concussion management. British Journals of Sports Medicine, 38, 654-655.

McCrory, P., Meeuwisse, W., Aubry, M., Cantu, B., Dvorak, J., Echemendia, R., ... Turner, M. (2013). Consensus statement on Concussion in Sport - The 4th International Conference on Concussion in Sport held in Zurich, November 2012. British Journal of Sports Medicine, 47, 250-258. Retrieved from https://doi.org/10.1016/j.pmrj.2013.02.012

McCrory, P., Meeuwisse, W., Dvorak, J., Aubry, M., Bailes, J., Broglio, S., ...Vos, P.(2017). Consensus statement on concussion in sport - the $5^{\text {th }}$ international conference on concussion in sport held in Berlin, October 2016. British Journal of Sports Medicine, 0, 1-10. doi:10.1136/bjsports-2017-097699

McCrory, P., Collie, A., Anderson, V. \& Davis, G. (2004). Can we manage sport related concussions in children the same way as in adults? Evidence based guidelines are required for the management of concussive injury in children. British Journal of Sports Medicine, 38, 516-519. doi: 10.1136/bjsm.2004.014811 
McKay, C.D., Schneider, K.J., Brooks, B.L., Mrazik, M. \& Emery, C.A. (2014). Baseline Evaluation in Youth Ice Hockey Players: Comparing Methods for Documenting Prior Concussions and Attention or Learning Disorders. Journal of Orthopaedic \& Sports Physical Therapy, 44(5), 329-335. doi: 10.2519/jospt.2014.5053

Nelson, L., Guskiewicz, K., Marshall, S., Hammeke, T., Barr, W., Randolph, C. \& McCrea, A. (2016a). Multiple Self-Reported Concussions Are More Prevalent in Athletes With ADHD and Learning Disability. Clinical Journal of Sports Medicine, 26(2), 120-127. doi: 10.1097/JSM.0000000000000207

Nelson, L., LaRoche, A., Pfaller, A., Lerner, E., Hammeke, C. Barr, W., Guskiewicz \& McCrea, M. (2016b). Prospective, Head-to-Head Study of Three Computerized Neurocognitive Assessment Tools (CNTs): Reliability and Validity for the Assessment of Sport-Related Concussion. Journal of the International Neuropsychological Society, 22, 24-37. doi:10.1017/S1355617715001101

Nicolson, R.I., Fawcett, A.J., Berry E.L., Jenkins I.H., Dean, P. \& Brooks, D.J. (1999). Association of abnormal cerebellar activation with motor learning difficulties in dyslexic adults. The Lancet, 353, 1662-1667. Retrieved from https://doi.org/10.1016/S0140-6736(98)09165-X

Rabinowitz, A. \& Arnett, P. (2012). Reading Based IQ Estimates and Actual Premorbid Cognitive Performance: Discrepancies in a College Athlete Sample. Journal of the 
International Neuropsychological Society, 18, 139-143.

doi:10.1017/S1355617711001275

Reynolds, E., Fazio, V.C., Sandel, N., Schatz, P. \& Henry, L.C. (2016). Cognitive

Development and the Immediate Postconcussion Assessment and Cognitive Testing: A

Case for Separate Norms in Preadolescents. Applied Neuropsychology: Child, 5(4), 283-

293. Retrieved from https://doi.org/10.1080/21622965.2015.1057637

SCAT3. British Journal of Sports Medicine 2013, 47, 259.

Schatz, P. \& Putz, B.O. (2006). Cross-validation of measures used for computer-based assessment of concussion. Applied Neuropsychology, 13, 151-159. Retrieved from https://doi.org/10.1207/s15324826an1303_2

Schatz, P. \& Robertshaw, S. (2014). Comparing Post-Concussive Neurocognitive Test Data to Normative Data Presents Risks for Under-Classifying "Above Average" Athletes. Archives of Clinical Neuropsychology, 29, 625-632. Retrieved from https://doi.org/10.1093/arclin/acu041

Schatz, P. \& Sandel, N. (2013). Sensitivity and specificity of the online version of ImPACT in high school and collegiate athletes. American Journal of sports Medicine, 41, 321-326. Retrieved from https://doi.org/10.1177/0363546512466038

Schneider, K.J., Emery C.A., Kang, J., Schneider, G.M. \& Meeuwisse, W.H. (2010). Examining Sport Concussion Assessment Tool ratings for male and female youth 
hockey players with and without a history of concussions. British Journal of Sports Medicine, 44(15), 1112-1117.

Silver, C.H., Ruff, R.M., Iverson, G.L., Barth, J.T., Broshek, D.K., Bush, S. S., Reynolds, C. R. (2008). Learning disabilities: The need for neuropsychological evaluation. Archives of Clinical Neuropsychology, 23 (2), 217-219. Retrieved from https://doi.org/10.1016/j.acn.2007.09.006

Zuckerman, S.L., Lee, Y.M., Odom, M.J., Solomon, G.S. \& Sills, A.K. (2013). Baseline neurocognitive scores in athletes with attention deficit-spectrum disorder and /or learning disability. Journal of Neurosurgery: Pediatrics, 12, 103-109. doi: 10.3171/2013.5.PEDS12524 
Table 1. Demographics of the study sample and comparisons of ImPACT® test results in LD group and typical learners.

\begin{tabular}{lccrc}
\hline & $\begin{array}{c}\text { Typical learners } \\
\mathrm{n}=1715 \\
\text { Mean }(\mathrm{SD})\end{array}$ & $\begin{array}{c}\text { LD group } \\
\mathrm{n}=108 \\
\text { Mean }(\mathrm{SD})\end{array}$ & $\mathrm{t}(\mathrm{df}=1821)$ & $\mathrm{p}$ \\
\hline Age & $16.15(1.79)$ & $16.35(1.57)$ & 1.88 & .26 \\
School years & $9.45(1.69)$ & $9.64(1.84)$ & -1.13 & .26 \\
Concussion history & $.43(.87)$ & $.59(1.11)$ & -1.86 & .06 \\
Hours slept night before & $8.16(1.05)$ & $8.17(1.05)$ & -0.07 & .95 \\
\hline Verbal memory & $82.98(10.42)$ & $78.07(11.54)$ & 4.71 & $<.001$ \\
Visual memory & $72.47(13.06)$ & $67.85(14.34)$ & 3.55 & $<.001$ \\
Visual motor speed & $35.20(6.43)$ & $31.42(7.20)$ & 5.89 & $<.001$ \\
Reaction time & $.63(.09)$ & $.65(.09)$ & -2.69 & $<.01$ \\
Total symptoms & $6.85(8.48)$ & $8.87(8.97)$ & -2.40 & .02 \\
\hline LD=learning disability & & & &
\end{tabular}


Table 2. Summary results from the multiple separate regression analysis, where neurocognitive scores are predicted for LD group and Typical learners based on age and concussion history.

\begin{tabular}{|c|c|c|c|c|c|c|c|c|c|c|}
\hline & \multicolumn{2}{|c|}{ Verbal Memory } & \multicolumn{2}{|c|}{ Visual Memory } & \multicolumn{2}{|c|}{ Visual Motor Speed } & \multicolumn{2}{|c|}{ Reaction Time } & \multicolumn{2}{|c|}{ Total Symptoms } \\
\hline & Age & $\begin{array}{l}\text { Concussion } \\
\text { history }\end{array}$ & Age & $\begin{array}{l}\text { Concussion } \\
\text { history }\end{array}$ & Age & $\begin{array}{l}\text { Concussion } \\
\text { history }\end{array}$ & Age & $\begin{array}{l}\text { Concussion } \\
\text { history }\end{array}$ & Age & $\begin{array}{l}\text { Concussion } \\
\text { history }\end{array}$ \\
\hline \multicolumn{11}{|l|}{$\begin{array}{l}\text { LD } \\
\text { group }\end{array}$} \\
\hline $\mathrm{B}$ & 0.29 & 0.05 & 0.23 & -0.05 & 0.52 & -0.04 & -0.31 & 0.07 & 0.08 & -0.05 \\
\hline SE B & 0.70 & 1.00 & 0.90 & 1.27 & 0.40 & 0.56 & 0.006 & 0.01 & 0.57 & 0.81 \\
\hline $\mathrm{p}$ & $\begin{array}{r}.003 \\
\mathrm{~N} \\
\end{array}$ & $\begin{array}{l}.64 \\
R^{2}=.09\end{array}$ & \multicolumn{2}{|c|}{ Note. $\mathrm{R}^{2}=.05$} & $\begin{array}{r}<.001 \\
\mathrm{No} \\
\end{array}$ & $\begin{array}{l}.68 \\
R^{2}=.27\end{array}$ & \multicolumn{2}{|c|}{ Note. $\mathrm{R}^{2}=.09$} & $\begin{array}{r}.43 \\
\mathrm{No} \\
\end{array}$ & $\begin{array}{l}.60 \\
\mathrm{R}^{2}=.007\end{array}$ \\
\hline \multicolumn{11}{|c|}{$\begin{array}{l}\text { Typical } \\
\text { Learners }\end{array}$} \\
\hline $\mathrm{B}$ & 0.07 & -0.03 & 0.04 & -0.03 & 0.36 & -0.001 & -0.23 & -0.01 & 0.06 & 0.10 \\
\hline SE B & 0.14 & 0.29 & 0.18 & 0.36 & 0.08 & 0.17 & 0.001 & 0.002 & 0.12 & 0.24 \\
\hline $\mathrm{p}$ & $\begin{array}{r}<.01 \\
\mathrm{Nc} \\
\end{array}$ & $\begin{array}{l}.23 \\
\mathrm{R}^{2}=.005\end{array}$ & $\begin{array}{r}.08 \\
\mathrm{No} \\
\end{array}$ & $\begin{array}{l}.29 \\
\mathrm{R}^{2}=.002\end{array}$ & $\begin{array}{r}<.001 \\
\mathrm{No} \\
\end{array}$ & $\begin{array}{l}.97 \\
R^{2}=.13\end{array}$ & $\begin{array}{r}<.001 \\
\mathrm{No}\end{array}$ & $\begin{array}{l}.67 \\
R^{2}=.05\end{array}$ & .02 & $\begin{array}{c}<.001 \\
\text { e. } R^{2}=.01\end{array}$ \\
\hline
\end{tabular}


Table 3. Linear model of predictors of verbal memory, visual memory, visual motor speed, reaction time and total symptoms.

\begin{tabular}{|c|c|c|c|c|c|c|c|c|c|c|c|c|c|c|c|c|c|c|c|c|}
\hline & \multicolumn{3}{|c|}{ Verbal memory } & \multicolumn{5}{|c|}{ Visual memory } & \multicolumn{4}{|c|}{ Visual motor speed } & \multicolumn{4}{|c|}{ Reaction time } & \multicolumn{4}{|c|}{ Total symptoms } \\
\hline & \multirow[b]{2}{*}{$\mathrm{b}$} & \multirow{2}{*}{$\begin{array}{l}\mathrm{SE} \\
\mathrm{B} \\
\end{array}$} & \multirow[b]{2}{*}{$\mathrm{t}$} & \multirow[b]{2}{*}{$\mathrm{p}$} & \multirow[b]{2}{*}{$\mathrm{b}$} & \multicolumn{3}{|l|}{ SE } & \multirow[b]{2}{*}{$\mathrm{b}$} & \multicolumn{3}{|l|}{ SE } & \multirow[b]{2}{*}{$\mathrm{b}$} & \multirow[b]{2}{*}{ SE B } & \multirow[b]{2}{*}{$\mathrm{t}$} & \multirow[b]{2}{*}{$\mathrm{p}$} & \multirow[b]{2}{*}{$\mathrm{b}$} & \multicolumn{2}{|l|}{ SE } & \multirow[b]{2}{*}{$\mathrm{p}$} \\
\hline & & & & & & $\mathrm{B}$ & $\mathrm{t}$ & $\mathrm{p}$ & & $\mathrm{B}$ & $\mathrm{t}$ & $\mathrm{p}$ & & & & & & $\mathrm{B}$ & $\mathrm{t}$ & \\
\hline \multirow[t]{2}{*}{ Constant } & 82.67 & 0.24 & 337.82 & $\mathrm{p}<.01$ & 72.18 & 0.31 & 234.82 & $\mathrm{p}<.01$ & 34.97 & .14 & 247.63 & $\mathrm{p}<.01$ & .63 & 0.002 & 315.71 & $\mathrm{p}<.01$ & 6.97 & 0.20 & 35.01 & $\mathrm{p}<.01$ \\
\hline & $\begin{array}{l}{[82.19,} \\
83.15]\end{array}$ & & & & $\begin{array}{l}{[71.58,} \\
72.78]\end{array}$ & & & & $\begin{array}{l}{[34.69,} \\
35,24]\end{array}$ & & & & $\begin{array}{l}{[.63,} \\
.64]\end{array}$ & & & & $\begin{array}{l}{[6.58,} \\
7.36]\end{array}$ & & & \\
\hline \multirow[t]{2}{*}{ LD } & -5.32 & 1.10 & -4.86 & $\mathrm{p}<.01$ & -4.99 & 1.40 & -3.57 & $\mathrm{p}<.01$ & -4.24 & .63 & -6.69 & $\mathrm{p}<.01$ & .02 & 0.009 & 2.94 & $\mathrm{p}<.01$ & 1.95 & 0.87 & 2.24 & $\mathrm{p}=.03$ \\
\hline & $\begin{array}{l}{[-7.47,} \\
-3.17]\end{array}$ & & & & $\begin{array}{l}{[-7.73} \\
-2.24]\end{array}$ & & & & $\begin{array}{l}{[-5,49} \\
-3.00]\end{array}$ & & & & $\begin{array}{l}{[.01,} \\
.04]\end{array}$ & & & & $\begin{array}{l}{[.24,} \\
3.66]\end{array}$ & & & \\
\hline \multirow[t]{2}{*}{ Age } & .51 & 0.14 & 3.63 & $\mathrm{p}<.01$ & .39 & 0.17 & 2.22 & $\mathrm{p}=.03$ & 1.36 & .08 & 16.87 & $\mathrm{p}<.01$ & -.01 & 0.001 & -10.31 & $\mathrm{p}<.01$ & .33 & 0.11 & 2.89 & $\mathrm{p}<.01$ \\
\hline & {$[.23, .78]$} & & & & {$[.04, .73]$} & & & & $\begin{array}{l}{[1.21,} \\
1.53]\end{array}$ & & & & $\begin{array}{l}{[-.01,-} \\
.01]\end{array}$ & & & & $\begin{array}{l}{[.11,} \\
.56]\end{array}$ & & & \\
\hline \multirow[t]{3}{*}{ LD x Age } & 1.82 & 0.70 & 2.60 & $\mathrm{p}=.01$ & 1.67 & 0.89 & 1.87 & $\mathrm{p}=.06$ & 1.05 & .34 & 3.12 & $\mathrm{p}<.01$ & -.01 & 0.006 & -1.06 & $\mathrm{p}=.29$ & .05 & 0.70 & .07 & $\mathrm{p}=.94$ \\
\hline & $\begin{array}{l}{[.45,} \\
3.20]\end{array}$ & & & & $\begin{array}{l}{[-.08,} \\
3.42]\end{array}$ & & & & $\begin{array}{l}{[.39} \\
1.71]\end{array}$ & & & & $\begin{array}{l}{[-.02,} \\
.01]\end{array}$ & & & & $\begin{array}{l}{[-1.32,} \\
1.41]\end{array}$ & & & \\
\hline & $\begin{array}{l}\text { Note. } \\
\mathrm{R}^{2}=.02\end{array}$ & & & & $\begin{array}{l}\text { Note. } \\
\mathrm{R}^{2}=.01\end{array}$ & & & & $\begin{array}{l}\text { Note. } \\
\mathrm{R}^{2}=.16\end{array}$ & & & & $\begin{array}{l}\text { Note. } \\
\mathrm{R}^{2}=.06\end{array}$ & & & & $\begin{array}{l}\text { Note. } \\
\mathrm{R}^{2}=.01\end{array}$ & & & \\
\hline
\end{tabular}


Table 4. Means and Standard Deviations for the ImPACT® composite scores and for the ImPACT® subtests in different age groups in typical learners.

\begin{tabular}{|c|c|c|c|c|c|c|c|c|}
\hline ImPACT scores & $\begin{array}{c}13 \text { years } \\
n=29 \\
M(S D)\end{array}$ & $\begin{array}{c}14 \text { years } \\
n=268 \\
M(S D)\end{array}$ & $\begin{array}{c}15 \text { years } \\
n=445 \\
M(S D)\end{array}$ & $\begin{array}{c}16 \text { years } \\
n=295 \\
M(S D)\end{array}$ & $\begin{array}{c}17 \text { years } \\
n=286 \\
M(S D)\end{array}$ & $\begin{array}{c}18 \text { years } \\
\mathrm{n}=170 \\
\mathrm{M}(\mathrm{SD})\end{array}$ & $\begin{array}{c}19 \text { years } \\
n=134 \\
M(S D)\end{array}$ & $\begin{array}{c}20 \text { years } \\
n=64 \\
M(S D)\end{array}$ \\
\hline $\begin{array}{l}\text { Verbal Memory } \\
\text { Composite Score }\end{array}$ & $81.24(11.58)$ & $82.52(10.11)$ & $82.47(10.58)$ & $82.55(10.72)$ & $83.27(10.25)$ & $84.26(10.04)$ & $84.37(10.06)$ & $84.23(9.89)$ \\
\hline $\begin{array}{l}\text { Word Memory total percent } \\
\text { correct }\end{array}$ & $91.47(5.67)$ & $91.85(6.78)$ & $91.66(6.63)$ & $91.92(6.73)$ & $92.09(6.51)$ & $92.77(5.99)$ & $92.38(5.57)$ & $91.04(5.97)$ \\
\hline $\begin{array}{l}\text { Symbol Match total correct } \\
\text { (hidden) }\end{array}$ & $6.38(1.76)$ & $6.20(2.06)$ & $6.22(2.08)$ & $6.10(2.08)$ & $6.18(1.99)$ & $6.24(2.14)$ & $6.16(2.21)$ & $6.39(2.00)$ \\
\hline $\begin{array}{l}\text { Three Letters pct. of total } \\
\text { letters correct }\end{array}$ & $81.61(18.91)$ & $86.94(14.78)$ & $86.79(14.15)$ & $88.09(14.36)$ & $89.21(13.68)$ & $90.82(13.11)$ & $92.34(11.86)$ & $90.94(13.41)$ \\
\hline $\begin{array}{l}\text { Visual Memory } \\
\text { Composite Score }\end{array}$ & $73.55(12.28)$ & $71.16(14.21)$ & $72.27(13.02)$ & $71.27(12.83)$ & $74.65(12.93)$ & $73.16(11.76)$ & $74.12(13.27)$ & $70.38(12.32)$ \\
\hline $\begin{array}{l}\text { Design Memory total } \\
\text { percent correct }\end{array}$ & $75.95(14.84)$ & $73.60(13.97)$ & $73.94(13.91)$ & $72.13(13.49)$ & $73.89(13.81)$ & $74.22(12.86)$ & $73.29(13.90)$ & $70.23(12.15)$ \\
\hline $\mathrm{X}-\mathrm{O}$ total correct (memory) & $8.55(1.92)$ & $8.25(2.40)$ & $8.47(2.22)$ & $8.46(2.15)$ & $9.05(2.16)$ & $8.66(1.96)$ & $8.99(2.32)$ & $8.48(2.11)$ \\
\hline Visual Motor Speed & $29.26(4.13)$ & $32.23(6.16)$ & $33.49(5.54)$ & $35.48(6.08)$ & $36.96(5.82)$ & $37.80(6.67)$ & $38.81(6.37)$ & $38.57(6.24)$ \\
\hline $\begin{array}{l}\mathrm{X}-\mathrm{O} \text { total correct } \\
\text { (interference) }\end{array}$ & $102.14(6.44)$ & $106.46(10.45)$ & $108.00(6.87)$ & $110.18(6.45)$ & $111.35(6.01)$ & $112.28(5.57)$ & $113.10(6.63)$ & $113.00(5.65)$ \\
\hline $\begin{array}{l}\text { Three Letters avg. counted } \\
\text { correctly }\end{array}$ & $10.99(2.71)$ & $12.61(3.79)$ & $13.33(3.48)$ & $14.47(3.83)$ & $15.36(3.71)$ & $15.84(4.25)$ & $16.45(4.04)$ & $16.29(3.95)$ \\
\hline Reaction Time & $.70(.10)$ & $.65(.09)$ & $.65(.09)$ & $.63(.09)$ & $.61(.08)$ & $.61(.09)$ & $.59(.08)$ & $.60(.08)$ \\
\hline $\begin{array}{l}\mathrm{X}-\mathrm{O} \text { avg. correct } \mathrm{RT} \\
\text { (interference) }\end{array}$ & $.58(.05)$ & $.55(.22)$ & $.53(.06)$ & $.52(.06)$ & $.51(.05)$ & $.50(.05)$ & $.50(.05)$ & $.51(.05)$ \\
\hline $\begin{array}{l}\text { Symbol Match avg. Correct } \\
\text { RT (visible) }\end{array}$ & $1.94(.61)$ & $1.79(.45)$ & $1.80(.52)$ & $1.76(.49)$ & $1.72(.54)$ & $1.73(.48)$ & $1.66(.53)$ & $1.71(.44)$ \\
\hline $\begin{array}{l}\text { Color Match avg. correct } \\
\text { RT }\end{array}$ & $.86(.13)$ & $.82(.15)$ & $.80(.17)$ & $.78(.14)$ & $.76(.12)$ & $.75(.12)$ & $.73(.09)$ & $.74(.12)$ \\
\hline Total Symptoms Score & $4.83(6.34)$ & $5.56(7.60)$ & $6.83(8.34)$ & $7.46(9.83)$ & $6.79(7.64)$ & $7.58(8.67)$ & $7.99(8.99)$ & $6.67(7.87)$ \\
\hline
\end{tabular}


Figure 1. Simple slopes equations of the regression of ImPACT® composite scores at learning diasability group and at typical learner group.
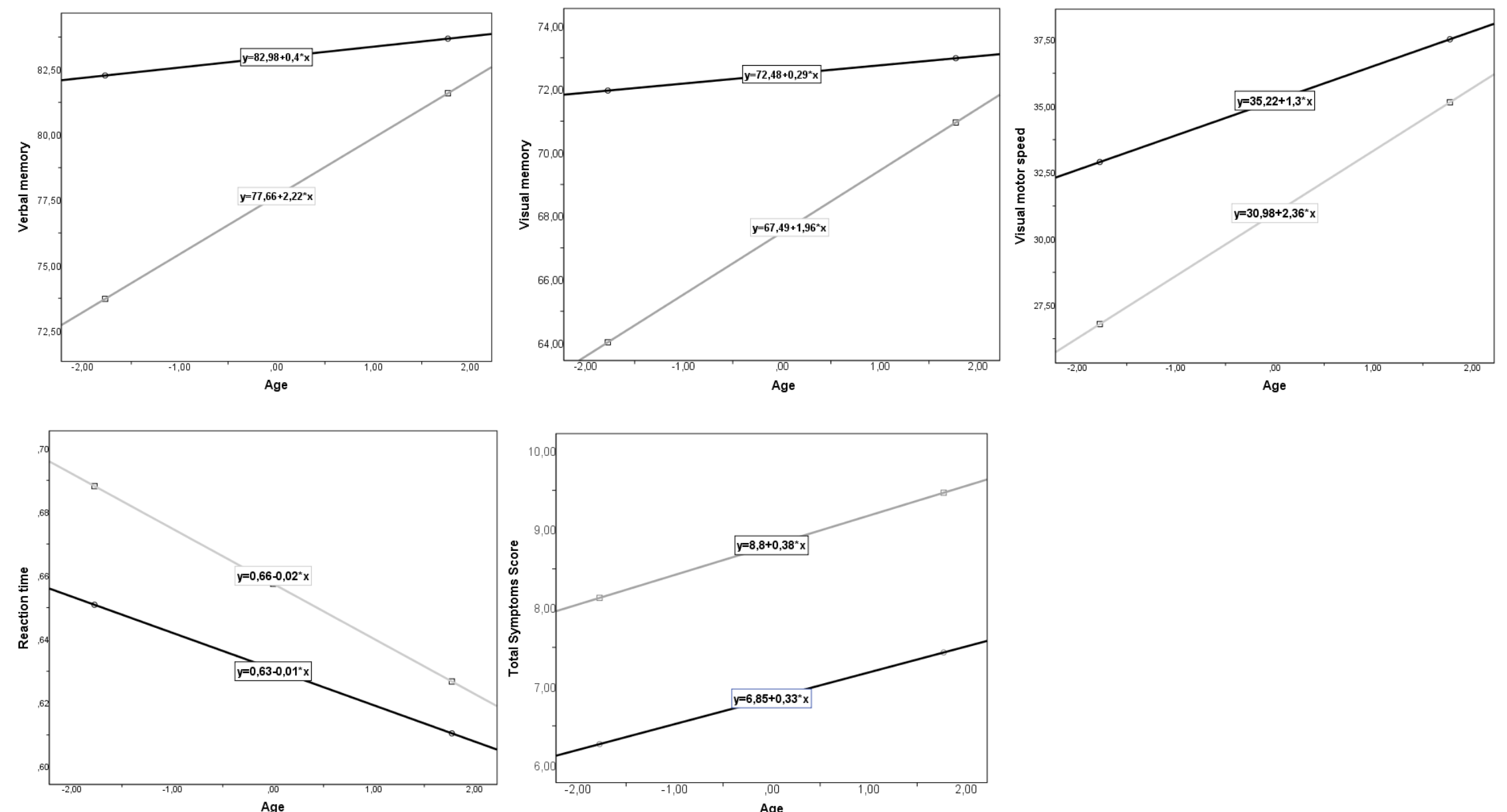

Age

\section{$\mathrm{O}=$ Typical learner group}

$$
\square=\text { LD group }
$$

